Artikel Penelitian

\title{
Screening Kandungan Plastik pada Minyak Goreng yang Digunakan pada Jajanan Pecel Lele
}

\author{
Merisca Gayatri Ryosa ${ }^{1}$, Yustini Alioes ${ }^{2}$, Husnil Kadri ${ }^{2}$
}

\begin{abstract}
Abstrak
Makanan bermanfaat jika ditinjau dari kualitas (aspek mikrobiologis dan fisik) dan nilai gizinya. Makanan dapat merugikan jika mengandung bahan tambahan pangan. Bahan tambahan pangan yang kerap digunakan adalah plastik. Tujuan penelitian ini adalah untuk mengetahui ada tidaknya kandungan plastik pada minyak goreng yang digunakan pada jajanan pecel lele serta jenis dan persentase kandungan derivat plastik didalamnya. Studi ini bersifat deskriptif kualitatif dengan metode pengambilan sampel secara total sampling. Penelitian dilakukan dari Oktober 2014 - Januari 2015 terhadap 5 sampel minyak goreng jajanan pecel lele di kelurahan Jati kota Padang. Sebanyak $100 \mathrm{ml}$ sampel dianalisis dengan GC-MS QP2010 jenis kolom RT-5MS pada temperatur kolum oven $80^{\circ} \mathrm{C}$, temperatur injeksi $200^{\circ} \mathrm{C}$, mode injeksi split, mode kontrol aliran dengan kecepatan linear, tekanan $162.2 \mathrm{kPa}$, total alirn $255.8 \mathrm{~mL} / \mathrm{menit}$, aliran kolom $2.50 \mathrm{~mL} /$ menit, kecepatan linear $58.3 \mathrm{~cm} /$ detik. Hasil penelitian ini menunjukkan 3 dari 5 sampel minyak goreng mengandung derivat plastik dengan persentase: sampel $1(7,88 \%)$, sampel $2(1,62 \%)$ dan sampel $3(15,65 \%)$. Derivat plastik yang ditemukan adalah benzene (phthalate), acrylic, dan cyclopentene.
\end{abstract}

Kata kunci: screening, plastik, minyak goreng, GC-MS

\section{Abstract}

The food has a benefit if it is considered from the quality (microbiologycal and physical) and the number of nutrient. The food can be harmful if it is contained by additionl substances. The additional substance frequently used is plastic. The objective of this study was to find out plastic content in cooking oil which is used in pecel lele and to the type of plastic compound and the percentage. This was a descriptive qualitative study with total sampling method. This study was taken from October 2014 until January 2015 using 5 samples of 100 ml cooking oil in Jati Padang which has been analyzed by GC-MS QP2010 type RT-5MS column with temperature column oven $80^{\circ} \mathrm{C}$, the temperature injection of $200^{\circ} \mathrm{C}$, split mode of injection, mode flow control with linear velocity, pressure $162.2 \mathrm{kPa}$, total flow of $255.8 \mathrm{~mL} / \mathrm{min}$, the flow field $2.50 \mathrm{~mL} / \mathrm{min}$, a linear speed of $58.3 \mathrm{~cm} / \mathrm{sec}$. The results showed that 3 of the 5 samples of cooking oils contained plastics with the percentages were the $1^{\text {st }}(7.88 \%)$, the $2^{\text {nd }}(1.62 \%)$, and the $3^{\text {rd }}(15.65 \%)$. The plastic compounds were benzene (phthalates), acrylic acid, and cyclopentene.

Keywords: screening, plastic, cooking oil, GC-MS

Affiliasi penulis: 1. Prodi Profesi Dokter FK Unand (Fakultas Kedokteran Universitas Andalas Padang), 2. Bagian Biokimia FK Unand.

Korespondensi: Merisca Gayatri Ryosa, Email:

meriscagr@gmail.com Telp: +62 82381344133

\section{PENDAHULUAN}

Makanan merupakan kebutuhan pokok yang tidak mungkin ditinggalkan. Salah satu faktor yang mempengaruhi kesehatan manusia adalah nilai gizi makanan yang dikonsumsi. Makanan yang dikonsumsi justru akan lebih banyak merugikan dibandingkan manfaatnya karena adanya zat aditif atau tambahan makanan didalamnya. ${ }^{1}$ Bahan Tambahan Pangan (BTP) adalah bahan untuk memperbaiki tekstur, warna, dan komponen mutu lainnya kedalam proses pengolahan pangan. ${ }^{2}$

Plastik merupakan bahan baru yang semakin berkembang. Plastik merupakan suatu polimer sintetik 
atau polimer termoplastik (polimer yang akan melunak jika dipanaskan) berbahan baku gas yang kemudian akan mengalami polimerisasi. Pada proses ini, tidak semua gas dapat terbentuk menjadi polimer sehingga sebagian gas teperangkap dalam keadaan tidak berikatan dan tidak dapat keluar. Zat ini mudah menguap apabila bersentuhan dengan benda bersuhu tinggi. Hasil penguapan kemudian masuk kedalam air, minyak, atau apa saja yang langsung bersinggungan dengan plastik. Apabila zat tersebut masuk ke dalam metabolisme dan menumpuk di dalam tubuh, kemungkinan terbentuk kanker akan semakin besar. Saat ini plastik digunakan dalam penggorengan makanan. Plastik dimasukkan kedalam minyak yang panas kemudan digunakan untuk menggoreng, maka sifat plastik yang mudah menguap akan masuk ke dalam makanan dan menimbulkan masalah dalam tubuh. $^{3}$

Berdasarkan data survey Badan Pengawasan Obat dan Makanan (BPOM) seperti yang dikutip oleh Hartanto (2012) dari sampling yang dilaksanakan 30 Balai BPOM di Indonesia dengan sampel 886 Sekolah Dasar yang tersebar di 30 kota di Indonesia, didapatkan sebanyak $35 \%$ sampel tidak memenuhi syarat. ${ }^{4}$ Dugaan adanya pangan gorengan mengandung plastik, salah satunya dapat diketahui dari bentuk bahan pangan goreng yang tetap tampak terlihat garing meskipun sesudah berjam-jam dimasak. ${ }^{5}$ Kelurahan Jati adalah salah satu kawasan mahasiswa yang ramai akan jajanan kaki lima. Telah ditemukan sembilan titik dari sepuluh sampel pedagang gorengan di kelurahan Jati yang menjadi sampel penelitian tentang penggunaan plastik pada minyak goreng positif menggunakan plastik dalam penggorengannya. ${ }^{6}$

Jajanan kaki lima yang juga ramai ditemukan di kawasan Jati adalah pecel lele. Pecel lele pada dasarnya adalah jajanan sehat karena terdiri dari ikan dan lalapan. Pemakaian minyak goring yang tidak baik tentu akan meningkatkan kadar produk sisa berupa peroksida. Oleh karena itu, perlu dilakukan penelitian dengan tujuan screening kandungan plastik pada minyak goreng yang terdapat pada jajanan pecel lele di kelurahan Jati Padang.
METODE

Penelitian ini menggunakan metode deskriptif kualitatif yang dilakukan di kelurahan Jati Kota Padang dari Oktober 2014 sampai Januari 2015. Metode pengambilan sampel yang digunakan adalah total sampling dengan jumlah sampel akhir sebanyak 5 sampel. Sampel yang digunakan berupa minyak goreng yang didapatkan dari penjual jajanan pecel lele sebanyak $100 \mathrm{ml}$ dengan kriteria sampel yang digunakan merupakan minyak baru ataupun minyak jelantah yang diambil sewaktu proses penggorengan sedang berlansung. Instrumen penelitian yang digunakan adalah Gas Chromatography Mass Spectrometry (GC-MS) untuk menentukan ada tidaknya derivate plastik pada sampel dan mengetahui jenis derivat plastik tersebut beserta dengan persentasenya. Pengukuran dengan GC-MS dilakukan dengan kondisi : jenis kolom RT-5MS dengan kolum oven $80^{\circ} \mathrm{C}$, temperatur injeksi $200^{\circ} \mathrm{C}$, mode injeksi split, mode control aliran dengan kecepatan linear, tekanan $162.2 \mathrm{kPa}$, total alirn $255.8 \mathrm{~mL} /$ menit, aliran kolom $2.50 \mathrm{~mL} /$ menit, kecepatan linear $58.3 \mathrm{~cm} /$ detik. Hasil ukur yang didapat berupa persentase dengan skala ukur rasio. Data yang diperoleh diolah secara deskriptif yang disertai tabel, narasi dan pembahasan serta diambil kesimpulan apakah terdapat derivat plastik pada 5 sampel minyak goreng.

\section{HASIL}

Sampel 1:

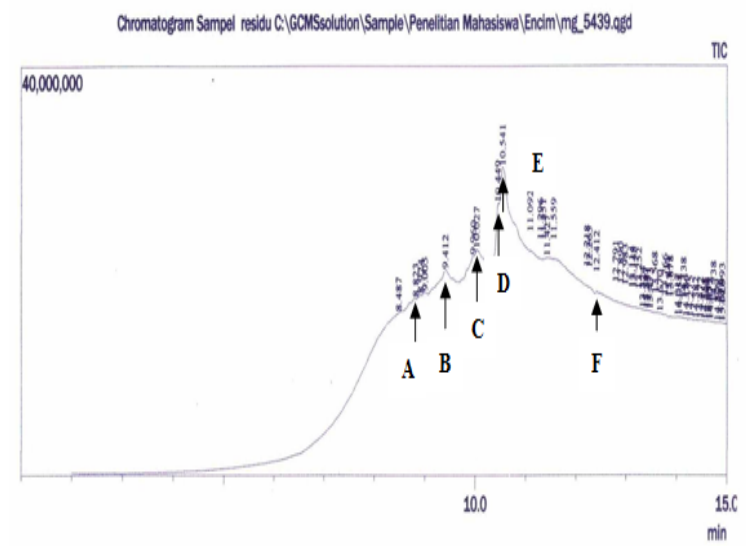

Gambar 1. Grafik analisa GC-MS sampel 1 
Tabel 1. Senyawa hasil analisa GC-MS sampel 1

\begin{tabular}{|c|c|c|c|c|}
\hline $\begin{array}{l}\text { Puncak } \\
\text { (peak) }\end{array}$ & $\begin{array}{c}\text { Waktu } \\
\text { Retensi } \\
\text { (min) }\end{array}$ & Senyawa & $\%$ & Ket \\
\hline$A$ & 8.823 & $\begin{array}{l}\text { Thiosulfuric } \\
\text { acid } \\
\text { (H2S2O3), S- } \\
\text { (2-aminoethyl) } \\
\text { ester }\end{array}$ & 4.13 & $\begin{array}{l}\text { Senyawa } \\
\text { normal }\end{array}$ \\
\hline B & 9.412 & $\begin{array}{l}\text { Octadecanoid } \\
\text { acid, (2- } \\
\text { phenyl-1,3- } \\
\text { dioxolan-4- } \\
\text { yl)methyl ester }\end{array}$ & 8.53 & $\begin{array}{c}\text { Senyawa } \\
\text { normal }\end{array}$ \\
\hline C & 10.027 & $\begin{array}{l}\text { Benzene, (1,2- } \\
\text { dimethylpropyl } \\
\text { )-(CAS) 2- } \\
\text { PHENYL 3- } \\
\text { METHYLBUT } \\
\text { ANE }\end{array}$ & 4.55 & $\begin{array}{l}\text { Derivat } \\
\text { plastik }\end{array}$ \\
\hline$D$ & 10.449 & $\begin{array}{l}1,2- \\
\text { Benzenedicar } \\
\text { boxylic acid, } \\
\text { bis( } 2- \\
\text { ethylhexyl) } \\
\text { ester (CAS) } \\
\text { Bis (2- } \\
\text { ethylhexyl) } \\
\text { phthalte }\end{array}$ & 3.33 & $\begin{array}{l}\text { Derivat } \\
\text { plastik }\end{array}$ \\
\hline$E$ & 10.541 & $\begin{array}{l}\text { Cinnamylcinna } \\
\text { mate }\end{array}$ & 11.22 & $\begin{array}{c}\text { Senyawa } \\
\text { normal }\end{array}$ \\
\hline $\mathrm{F}$ & 12.412 & $\begin{array}{l}\text { Thiosulfuric } \\
\text { acid } \\
\text { (H2S2O3), S- } \\
\text { (2-aminoethyl) } \\
\text { ester }\end{array}$ & 4.42 & $\begin{array}{c}\text { Senyawa } \\
\text { normal }\end{array}$ \\
\hline
\end{tabular}

\section{Sampel 2:}

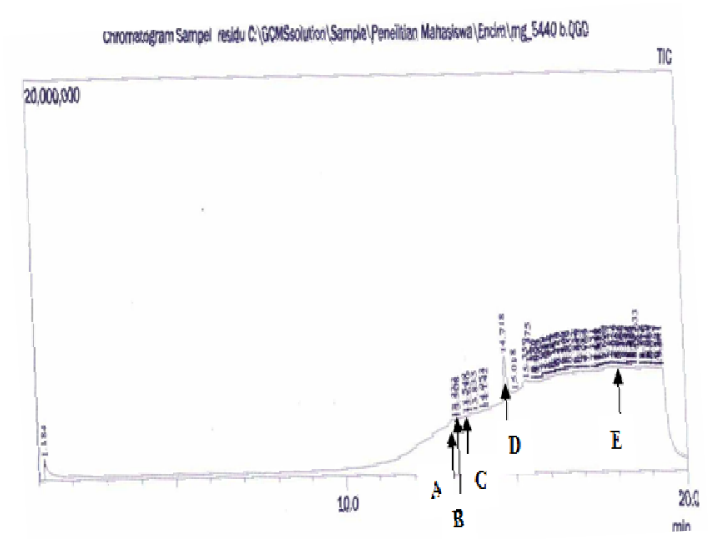

Gambar 2. Grafik analisa GC-MS sampel 2
Tabel 2. Senyawa hasil analisa GC-MS sampel 2

\begin{tabular}{|c|c|c|c|c|}
\hline $\begin{array}{c}\text { Puncak } \\
\text { (peak) }\end{array}$ & $\begin{array}{c}\text { Waktu } \\
\text { Retensi } \\
\text { (min) }\end{array}$ & Senyawa & $\%$ & Ket \\
\hline$A$ & 13.233 & $\begin{array}{l}\text { Pentanoic acid, } \\
\text { 4-nitro-, methyl } \\
\text { 4- } \\
\text { nitropentanoate }\end{array}$ & 9.97 & $\begin{array}{c}\text { Senyawa } \\
\text { normal }\end{array}$ \\
\hline B & 13.308 & $\begin{array}{l}\text { Hexadecanoic } \\
\text { acid, 2-hydroxy- } \\
\text { 1,3-propanedyl } \\
\text { ester (CAS) } \\
\text { GLYCEROL 1,3- } \\
\text { DIHEXADECAN } \\
\text { OATE }\end{array}$ & 0.68 & $\begin{array}{c}\text { Senyawa } \\
\text { normal }\end{array}$ \\
\hline C & 13.549 & $\begin{array}{l}\text { 2,6-DIMETHYL - } \\
\text { 3-OCTANOL }\end{array}$ & 2.28 & $\begin{array}{c}\text { Senyawa } \\
\text { normal }\end{array}$ \\
\hline D & 14.718 & $\begin{array}{l}2,6,10,14,18,22- \\
\text { Tetracosahexae } \\
\text { ne, } \\
2,6,10,15,19,23- \\
\text { hexamethyl- } \\
\text { (CAS) Squalene }\end{array}$ & 9.84 & $\begin{array}{c}\text { Senyawa } \\
\text { normal }\end{array}$ \\
\hline E & 18.057 & $\begin{array}{l}\text { Acylic acid decyl } \\
\text { ester }\end{array}$ & 1.62 & $\begin{array}{l}\text { Derivat } \\
\text { plastik }\end{array}$ \\
\hline
\end{tabular}

Sampel 3:

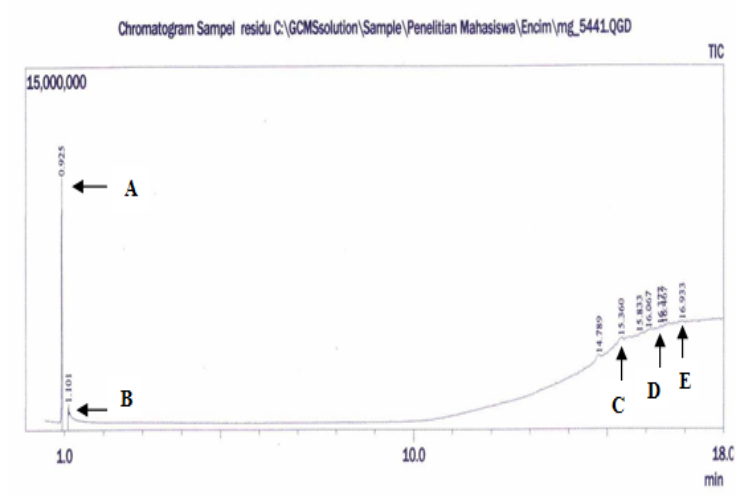

Gambar 3. Grafik analisa GC-MS sampel 3

Tabel 3. Senyawa hasil analisa GC-MS sampel 3

\begin{tabular}{|c|c|c|c|c|}
\hline $\begin{array}{l}\text { Puncak } \\
\text { (peak) }\end{array}$ & $\begin{array}{c}\text { Waktu } \\
\text { Retensi } \\
\text { (min) }\end{array}$ & Senyawa & $\%$ & Ket \\
\hline $\mathrm{A}$ & 0.925 & $\begin{array}{l}\text { Ethanol (CAS) } \\
\text { Ethylalcohol }\end{array}$ & 35.43 & $\begin{array}{c}\text { Senyawa } \\
\text { normal }\end{array}$ \\
\hline B & 1.101 & $\begin{array}{l}\text { Trans-3,5- } \\
\text { Dideutero } \\
\text { hydroxycyclopen } \\
\text { tene }\end{array}$ & 15.65 & $\begin{array}{l}\text { Derivat } \\
\text { plastik }\end{array}$ \\
\hline C & 15.360 & $\begin{array}{l}\text { 9-Octdecenoic } \\
\text { acid (Z)-(CAS) } \\
\text { Oleic acid }\end{array}$ & 4.73 & $\begin{array}{c}\text { Senyawa } \\
\text { normal }\end{array}$ \\
\hline D & 16.377 & $\begin{array}{l}\text { Hexadecanoic } \\
\text { acid,1- } \\
\text { (hydroxymethyl)- } \\
\text { 1,2-ethanediyl } \\
\text { ester (CAS) 1,2- } \\
\text { Dipalmitin }\end{array}$ & 2.34 & $\begin{array}{c}\text { Senyawa } \\
\text { normal }\end{array}$ \\
\hline$E$ & 16.933 & $\begin{array}{l}\text { DODECANOIC } \\
\text { ACID, 12- } \\
\text { HYDROXY }\end{array}$ & 3.32 & $\begin{array}{c}\text { Senyawa } \\
\text { normal }\end{array}$ \\
\hline
\end{tabular}

Jurnal Kesehatan Andalas. 2017; 6(1) 


\section{Sampel 4:}

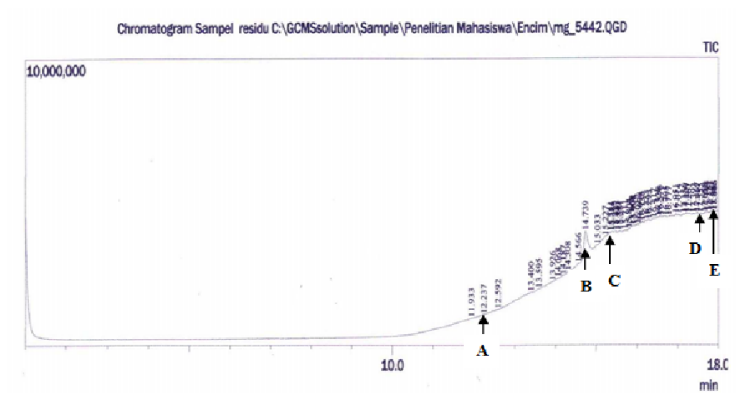

Gambar 4. Grafik analisa GC-MS sampel 4

Tabel 4. Senyawa hasil analisa GC-MS sampel 4

\begin{tabular}{|c|c|c|c|c|}
\hline $\begin{array}{c}\text { Puncak } \\
\text { (peak) }\end{array}$ & $\begin{array}{c}\text { Waktu } \\
\text { Retensi } \\
\text { (min) }\end{array}$ & Senyawa & $\%$ & Ket \\
\hline$A$ & 12.237 & $\begin{array}{l}\text { Hexadecanoic acid } \\
\text { (CAS) Palmitic } \\
\text { acid }\end{array}$ & 0.94 & $\begin{array}{c}\text { Senyawa } \\
\text { normal }\end{array}$ \\
\hline B & 14.739 & $\begin{array}{l}2,6,10,14,18,22- \\
\text { Tetracosahexaene, } \\
2,6,10,15,19,23- \\
\text { hexamethyl- (CAS) } \\
\text { Squalene }\end{array}$ & 4.56 & $\begin{array}{c}\text { Senyawa } \\
\text { normal }\end{array}$ \\
\hline $\mathrm{C}$ & 15.351 & $\begin{array}{l}\text { 9-Octadecenoic } \\
\text { acid (Z)-(CAS) } \\
\text { Oleic acid }\end{array}$ & 2.03 & $\begin{array}{c}\text { Senyawa } \\
\text { normal }\end{array}$ \\
\hline$D$ & 17.821 & $\begin{array}{l}\text { 9-Octadecanoic } \\
\text { acid, (2-phenyl- } \\
\text { 1,3-dioxolan-4- } \\
\text { yl)methyl ester. }\end{array}$ & 0.98 & $\begin{array}{c}\text { Senyawa } \\
\text { normal }\end{array}$ \\
\hline$E$ & 19.325 & $\begin{array}{l}\text { 9-Octadecenoic } \\
\text { acid (Z)-(CAS) } \\
\text { Oleic acid }\end{array}$ & 3.36 & $\begin{array}{l}\text { Senyawa } \\
\text { normal }\end{array}$ \\
\hline
\end{tabular}

\section{Sampel 5:}

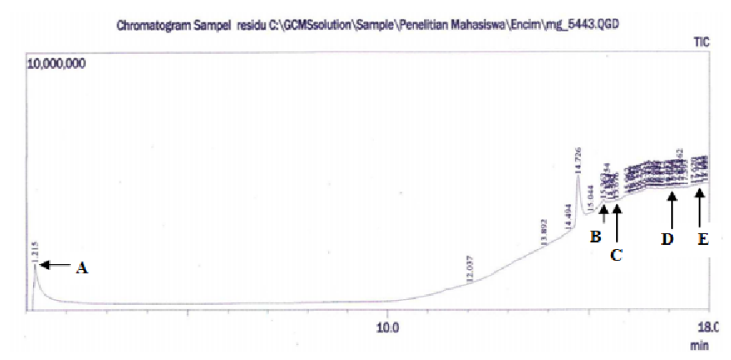

Gambar 5. Grafik analisa GC-MS sampel 5.
Tabel 5. Senyawa hasil analisa GC-MS sampel 5

\begin{tabular}{|c|c|c|c|c|}
\hline $\begin{array}{c}\text { Puncak } \\
\text { (peak) }\end{array}$ & $\begin{array}{l}\text { Waktu } \\
\text { Retensi } \\
\text { (min) }\end{array}$ & Senyawa & $\%$ & Ket \\
\hline$A$ & 1.215 & $\begin{array}{l}\text { Ethanol (CAS) Ethyl } \\
\text { alcohol }\end{array}$ & 2.16 & $\begin{array}{c}\text { Senyawa } \\
\text { normal }\end{array}$ \\
\hline B & 15.363 & $\begin{array}{l}\text { 9-Octadecenoic acid } \\
\text { (Z)-(CAS) oleic acid }\end{array}$ & 5.34 & $\begin{array}{c}\text { Senyawa } \\
\text { normal }\end{array}$ \\
\hline C & 15.676 & $\begin{array}{l}\text { Decanoic acid (CAS) } \\
\text { Capric acid }\end{array}$ & 0.92 & $\begin{array}{c}\text { Senyawa } \\
\text { normal }\end{array}$ \\
\hline $\mathrm{D}$ & 16.093 & $\begin{array}{l}\text { Oxiraneundecanoic } \\
\text { acid, 3-penthyl-, } \\
\text { methyl ester, cis- } \\
\text { (CAS) METHYL } \\
\text { CIS-12,13- } \\
\text { EPOXISTEARATE }\end{array}$ & 0.84 & $\begin{array}{c}\text { Senyawa } \\
\text { normal }\end{array}$ \\
\hline E & 17.393 & $\begin{array}{l}\text { Hexadecanoic acid, } \\
\text { 2-hydroxy-1,3- } \\
\text { propanedyl ester } \\
\text { (CAS) GLYCEROL } \\
1,3- \\
\text { DIHEXDECANOATE }\end{array}$ & 1.04 & $\begin{array}{c}\text { Senyawa } \\
\text { normal }\end{array}$ \\
\hline
\end{tabular}

Berdasarkan hasil dari analisis minyak goreng yang digunakan pada jajanan pecel lele di kelurahan Jati kota Padang, sampel yang positif menggunakan plastik disajikan dibawah ini.

Tabel 6. Hasil analisis sampel dengan GC-MS
No

Sampel

benzene, $(1,2-$

dimethylpropyl)-(CAS), 1,2-

Benzenedicarboxylic

acid,bis(2-ethylhexyl)ester

(CAS) bis (2-ethylhexyl)

phthalate

2

3

acrylic acid decyl ester
Trans-3,5-Dideutero

hydroxycyclopentene
Konsentrasi

$7,88 \%$

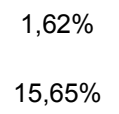

$15,65 \%$ 


\section{PEMBAHASAN}

Identifikasi senyawa plastik yang terkandung dalam minyak dianalisis menggunakan GC-MS menunjukkan peak (puncak) senyawa yang terdeteksi kemudian diidentifikasi melalui data massa spektrum yang ada pada instrumen.

\section{Sampel 1}

Ada 30 senyawa yang teridentifikasi dengan komponen utama adalah cinnamyl cinnamate $(11,22 \%)$, thiosulfuric acid $\left(\mathrm{H}_{2} \mathrm{~S}_{2} \mathrm{O}_{3}\right), \mathrm{S}$-(2-aminoethyl) ester (8,55\%), benzene,(1,2-dimethylpropyl)-(CAS), 1,2-Benzenedicarboxylic acid,bis(2-ethylhexyl)ester (CAS) bis (2-ethylhexyl) phthalate $(7,88 \%)$.

Cinnamyl cinnamate merupakan senyawa asam lemak aromatik yang normal terdapat pada minyak goreng. ${ }^{7}$ Asam tiosulfat $\left(\mathrm{H}_{2} \mathrm{~S}_{2} \mathrm{O}_{3}\right)$ adalah komponen yang lazim ditemukan pada minyak curah yang dalam bentuk garamnya digunakan untuk penentuan bilangan peroksida. ${ }^{8}$ Phthalate merupakan senyawa tambahan pada pembuatan plastik yang berfungsi sebagai plasticizer yaitu memberikan sifat lembut dan fleksibel pada polimer Polivinil Klorida (PVC). ${ }^{9} \quad$ Komponen utama Sampel 1 dapat disimpulkan mengandung produk dari plastik.

\section{Sampel 2}

Ada 30 senyawa yang teridentifikasi dengan komponen utama adalah pentanoic acid, 4-nitro-, methyl ester (CAS) Methyl 4-nitropentanoate (9,97\%) dan 2,6,10,14,18,22-tetracosahexaena, 2,6,10,15,19, 23-hexamethyl- (CAS)Squalene (9,84\%). Sampel 2 ini juga mengandung senyawa berbahaya acrylic acid decyl ester $(1,62 \%)$.

Pentanoic acid (asam pentanoat) yang memiliki nama trivial asam valerat adalah jenis asam lemak jenuh rantai lurus dengan atom $\mathrm{C}$ ganjil yang merupakan komponen yang normal ada pada minyak goreng. ${ }^{10}$ Squalene adalah senyawa bukan minyak karena tidak memiliki gugusan $\mathrm{COOH}$, namun dapat terkandung dalam jumlah minimal pada kelapa sawit. ${ }^{11}$ Acrylic merupakan produk dari plastik jenis polypropylene (PP). ${ }^{12}$ Salah satu komponen sampel 2 dapat disimpulkan mengandung produk dari plastik.

\section{Sampel 3}

Ada 30 senyawa yang teridentifikasi dengan komponen utama adalah ethanol (CAS) ethyl alcohol (35.43\%), 9-Octadecenoic acid (Z)- (CAS) Oleic acid $(24,97 \%)$, Trans-3,5-Dideutero hydroxy cyclopentene $(15,65 \%)$.

Ethanol (CAS) ethyl alcohol merupakan senyawa yang ditemukan pada pemakaian minyak jelantah yang lazim digunakan oleh pedagang. ${ }^{8}$ Oleic acid atau asam oleat adalah kandungan normal pada minyak. ${ }^{13}$ Cyclopentene adalah senyawa yang terdapat pada crude oil yang merupakan hasil dari dekomposisi limbah plastik jenis polypropylene (PP). ${ }^{14}$ Komponen utama Sampel 3 dapat disimpulkan mengandung produk dari plastik.

\section{Sampel 4}

Ada 30 senyawa yang teridentifikasi dengan komponen utama adalah 9-Octadecenoic acid (Z)(CAS) Oleic acid (6,37\%), dan 2,6,10,14,18,22tetracosahexaene, 2,6,10,15,19,23-hexamethyl- (CAS) Squalene $(4,56 \%)$.

Oleic acid atau asam oleat adalah kandungan normal pada minyak. ${ }^{13}$ Squalene adalah senyawa bukan minyak karena tidak memiliki gugusan $\mathrm{COOH}$, namun dapat terkandung dalam jumlah minimal pada kelapa sawit. ${ }^{11}$ Komponen utama Sampel 4 disimpulkan senyawa yang normal dalam minyak.

\section{Sampel 5}

Ada 30 senyawa yang teridentifikasi dengan komponen utama adalah 9-Octadecenoic acid (Z)(CAS) Oleic acid (5,34\%) dan Ethanol (CAS) ethyl alcohol $(2,16 \%)$.

Oleic acid atau asam oleat adalah kandungan normal pada minyak. ${ }^{13}$ Ethanol (CAS) ethyl alcohol adalah senyawa yang ditemukan pada pemakaian minyak jelantah yang lazim digunakan oleh pedagang. ${ }^{8}$ Komponen utama Sampel 5 disimpulkan senyawa yang normal dalam minyak.

Penelitian tentang praktik penggunaan plastik juga telah dilakukan di kawasan Jati Padang dengan hasil berupa ditemukannya 9 dari 10 sampel positif menggunakan plastik sebagai bahan tambahan 
pangan. ${ }^{6}$ Hasil penelitian tersebut hampir sama dengan penelitian ini yaitu adanya penggunaan plastik yang ditambahkan ke minyak goreng dengan hasil 3 dari 5 sampel yang diambil dari penjual jajanan pecel lele di kelurahan Jati kota Padang mengandung senyawa plastik.

Persentase minyak goreng yang mengandung senyawa plastik adalah: Sampel $1(7.88 \%), 2(1.62 \%)$, dan $3(15.65 \%)$. Persentase yang didapatkan memang relatif tidak tinggi, namun plastic akan tetap menjadi toksik pada tubuh meskipun dalam kadar yang sangat rendah karena sifat plastik yang tidak dapat diuraikan oleh enzim. Meskipun demikian penelitian ini memiliki keterbatasan, namun diharapkan tetap dapat memberikan manfaat dalam upaya pendeteksian dan perlindungan konsumen terhadap kasus kecurangan produsen sehingga resiko terjadinya efek plastic terhadap kesehatan dalam jangka waktu yang lama seperti kanker, cacat lahir, perubahan genetik, bronkiitis kronik, penyakit kulit, tuli, gangguan penglihatan, gangguan pencernaan, disfungsi hati, asma, perubahan hormon, gangguan sistem imun, dan reproduksi dapat diturunkan.

Ketelitian masyarakat sebelum membeli makanan menjadi salah satu kunci agar dapat terhindar dari makanan yang mengandung plastik. Makanan yang mengandung plastik akan tampak dan terasa gurih dan garing walaupun sudah berjam-jam dimasak dibandingkan dengan makanan yang digoreng dengan minyak biasa. Terkadang akan tampak bercak putih mengkilap plastic pada makanan. Namun, bercak ini baru akan terlihat apabila konsentrasi plastic dalam minyak goring sangat tinggi. Penelitian ini diharapkan dapat memberikan ide dan dapat menjadi pembanding bagi penelitian selanjutnya.

\section{SIMPULAN}

Sampel minyak goreng yang mengandung senyawa plastik adalah sampel 1, 2, dan 3 . Persentase konsentrasi senyawa plastik pada minyak goreng adalah $7.88 \%$ pada sampel $1,1.62 \%$ pada sampel 2 dan $15.65 \%$ pada sampel 3 .

\section{DAFTAR PUSTAKA}

1. Kristianingrum $S$. Pengawet makanan yang aman bagi kesehatan (skripsi). Yogyakarta: Universitas Negeri Yogyakarta; 2006.

2. Hardiansyah, Sumali. Pengendalian mutu dan keamanan pangan. Jakarta: Koswara; 2001.

3. Fatimah A. Hidup kita dekat dengan senyawa kimia berbahaya. [serial online] 2012 (diunduh 6 September 2014). Tersedia dari: URL: HYPERLINK http://humaniora.kompasiana.com

4. Hartanto D. Masih ditemukan gorengan bercampur plastik di jaksel. [serial online] 2012 (diunduh 6 September 2014). Tersedia dari: URL: HYPERLINK http://ikebayoran.com

5. Burhani R. Masyarakat diminta waspadai gorengan mengandung plastik. [serial online] 2013 (diunduh 6 September 2014). Tersedia dari: URL: HYPERLINK http://www.antaranews.com

6. Sari AR. Screening kandungan plastik pada minyak goreng yang terdapat pada gorengan di jati padang (skripsi). Padang: Fakultas Kedokteran Universitas Andalas; 2013.

7. Opdyke. Monographs on fragrance raw material. Australia: Pergamon Press (Aust); 2011.

8. Aminah S. Bilangan peroksida minyak goreng curah dan sifat organoleptik tempe pada pengulngan penggorengan. Jurnal Pangan dan Gizi Universitas Muhammadiyah Semarang. 2010; 1(1): 7-14.

9. Irawan S, Supeni G. Krakterisasi migrasi kemasan dan peralatan rumah tangga berbasis polimer. Jurnal Kimiadan Kemasan Balai Besar Kimia dan Kemasan.2013; 2(35):105-12.

10. Winarni, Sumarto W, Mntini S. Penetralan dan adsorbsi minyak goreng bekas menjadi minyak goreng layak pakai konsumsi. Jurnal Universitas Negeri Semarang.2010; 8(1):46-56.

11. Gunstone F. Vegetable oils in food technology: composition, properties, and uses. Edisi ke-2. United States: John Wiley \& Sons; 2011.

12. Wang JC. Polymeric materials. Dalam: Wang JC, Liu CM, Zhao QC, Dong X. Materials design, processing, and applications. 2013.hlm. 690(693). 
13. Mursalin, Hariyadi P, Purnomo EH, Fardiaz D, Andarwulan $\mathrm{H}$. Pengaruh laju pendinginan, suhu, dan lama kristalisasi pada produk triasilgliserol dan sifat pelelehan produk fraksionasi minyak kelapa. Jurnal IImu Pertanian Indonesia. 2013;18(1):6-14.
14. Naimah S, Nuraeni C, Rumonday I, Jati BN, Ermawati R. Dekomposisi limbah plastik polypropylene dengan metode pirolisis. Journal of Material Science Balai Besar Kimia dan Kemasan. 2012;13(3):226-9. 